\title{
Relationship between Adherence to Oral Antibiotics and Postdischarge Clinical Outcomes among Patients Hospitalized with Staphylococcus aureus Skin Infections
}

\author{
Samantha J. Eells, ${ }^{\text {a,b,c }}$ Megan Nguyen, $^{\text {a,d }}{ }^{\text {Jina Jung, }}{ }^{\text {d }}$ Raul Macias-Gil, ${ }^{\text {a }}$ Larissa May, $^{\text {e }}$ Loren G. Miller $^{\text {a,b }}$ \\ Division of Infectious Diseases, Los Angeles Biomedical Research Institute at Harbor-UCLA Medical Center, Torrance, California, USA; David Geffen School of Medicine at \\ UCLA and Harbor-UCLA Medical Center, Los Angeles, California, USA ${ }^{\text {; }}$; Science 37, Inc., and Department of Epidemiology, UCLA Fielding School of Public Health, Los \\ Angeles, California, USA; College of Pharmacy, Western University of Health Sciences, Pomona, California, USA ; Department of Emergency Medicine, University of \\ California-Davis, Sacramento, California, USA
}

Skin and soft tissue infections are common and frequently recur. Poor adherence to antibiotic therapy may lead to suboptimal clinical outcomes. However, adherence to oral antibiotic therapy for skin and soft tissue infections and its relationship to clinical outcomes have not been examined. We enrolled adult patients hospitalized with uncomplicated skin and soft tissue infections caused by Staphylococcus aureus who were being discharged with oral antibiotics to complete therapy. We fit the participants' pill bottles with an electronic bottle cap that recorded each pill bottle opening, administered an in-person standardized questionnaire at enrollment, 14 days, and 30 days, and reviewed the participants' medical records to determine outcomes. Our primary outcome was poor clinical response, defined as a change in antibiotic therapy, new incision-and-drainage procedure, or new skin infection within 30 days of hospital discharge. Of our 188 participants, 87 had complete data available for analysis. Among these participants, $40(46 \%)$ had a poor clinical response at 30 days. The mean electronically measured adherence to antibiotic therapy was significantly different than the self-reported adherence ( $57 \%$ versus $96 \% ; P<0.0001)$. In a multivariable model, poor clinical response at 30 days was associated with patients having lower adherence, being nondiabetic, and reporting a lack of illicit drug use within the previous 12 months $(P<0.05)$. In conclusion, we found that patient adherence to oral antibiotic therapy for a skin and soft tissue infection after hospital discharge was low (57\%) and associated with poor clinical outcome. Patients commonly overstate their medication adherence, which may make identification of patients at risk for nonadherence and poor outcomes challenging. Further studies are needed to improve postdischarge antibiotic adherence after skin and soft tissue infections.

\footnotetext{
kin infections are a common reason for physician visits and hospital admission $(1,2)$. Staphylococcus aureus is the most common cause of skin infections in the community $(3,4)$. Recurrent and/or relapse skin infections are commonly reported after an initial S. aureus skin infection (5-7). Rates of recurrence have exceeded $50 \%$ in some populations $(5,8,9)$.

Reasons for the failure of a skin infection to resolve are poorly understood but are likely to be due to host and behavior factors, inadequate medical and/or surgical therapy, and possibly pathogen-associated factors (10). In other chronic and acute infections, medication adherence is frequently suboptimal and associated with worse clinical outcomes (11-13). However, there are no studies to date evaluating antibiotic adherence, or the relationship between adherence and clinical outcome, among patients experiencing skin infections.

Poor adherence to medication regimens is common across all disease entities. Low adherence contributes to a worsening of the patient's condition, death, and increased health care costs (14). Even in clinical trials, where study participants receive increased support, mean reported adherence rates are 43 to $78 \%$ (14). Other investigations addressing adherence among patients taking antibiotics have found adherence rates of 57 to $78 \%$ by patient report $(15,16)$. Antibiotic treatment of $S$. aureus skin infections has unique challenges. Antibiotics for skin infections are typically taken two to four times daily for 1 to 2 weeks, and side effects such as gastrointestinal symptoms are common $(17,18)$. Both high dosing frequency and adverse drug effects are associated with lower medication adherence (14).
}

We hypothesized that patients with lower rates of adherence to their antibiotic regimen will have poor clinical outcomes. To examine adherence to and the subsequent clinical outcome of the prescribed antibiotic regimen after hospital discharge among patients experiencing a $S$. aureus skin infection, we enrolled patients and monitored them to determine their antibiotic adherence and clinical outcomes.

\section{MATERIALS AND METHODS}

Study design. This prospective cohort investigation took place at HarborUCLA Medical Center, a 400-bed tertiary-care county hospital, from November 2009 to March 2012. Potentially eligible patients were identified via daily screening of microbiology laboratory results for S. aureus-positive wound cultures by research coordinators. Adult patients were eligible for the study if (i) they had a confirmed S. aureus skin infection without bacteremia, osteomyelitis, or endocarditis or a hardware-associated infec-

Received 30 October 2015 Returned for modification 19 November 2015 Accepted 25 February 2016

Accepted manuscript posted online 29 February 2016

Citation Eells SJ, Nguyen M, Jung J, Macias-Gil R, May L, Miller LG. 2016. Relationship between adherence to oral antibiotics and postdischarge clinical outcomes among patients hospitalized with Staphylococcus aureus skin infections Antimicrob Agents Chemother 60:2941-2948. doi:10.1128/AAC.02626-15.

Address correspondence to Loren G. Miller, Lgmiller@ucla.edu.

Copyright @ 2016, American Society for Microbiology. All Rights Reserved. 
tion, (ii) the infection occurred $<72 \mathrm{~h}$ after admission to the medical center, and (iii) the treating team planned to discharge the patient on oral antibiotic therapy for $S$. aureus for up to 2 weeks. This investigation was approved by the Los Angeles Biomedical Research Institute at HarborUCLA Medical Center Institutional Review Board.

Study visits. Participants completed an in-person study visit at enrollment and 14 days postdischarge and a phone visit at 30 days postdischarge. At each visit, a standardized instrument that used questions from a previously reported investigation of risk factors for skin infections was used to assess risk factors for relapse or recurrent infection as well as self-reported adherence $(9,19)$. The survey was based on previous surveys used for measuring adherence to treatment for infectious diseases (20). Predictors of nonadherence were based on established conceptual models of adherence $(14,21)$.

Data collection. Upon hospital discharge, the oral antibiotic prescribed to continue treatment of the participant's $S$. aureus infection was placed into a pill bottle fitted with a Medication Event Monitoring System (MEMS) electronic bottle cap. The MEMS cap measures the date and time each time that the pill bottle is opened or closed (22). The MEMS cap was collected and information was downloaded at the day 14 visit for analysis. Antibiotic treatment was determined by the participants' treating providers.

A study physician blind to the adherence results conducted a review of the participants' medical records. The initial hospitalization was reviewed to confirm eligibility criteria and discharge medications. Data on subsequent hospitalizations, clinic visits, and microbiology results were collected during the 30 days of follow-up for the study.

Data analysis. The primary outcome was clinical response after 30 days of follow-up, with poor clinical response being defined as the presence of any of the following events, as determined by patient report and/or review of the medical chart: (i) relapse of skin infection, (ii) new skin infection, (iii) receipt of prolonged antibiotic therapy for skin infection, (iv) receipt of new antibiotic therapy or change in therapy for skin infection, or (v) new incision-and-drainage procedure. Patients were considered to have prolonged antibiotic therapy if the provider deemed it necessary to extend the duration of therapy beyond that originally anticipated at the follow-up visit. Secondary outcomes of interest included (i) clinical response after 14 days of follow-up using the same definition of poor clinical response as that for the primary outcome, (ii) predictors of adherence to antibiotic therapy, and (iii) evaluation of the participants' attitudes and beliefs in regard to taking antibiotics.

Adherence was calculated based on the proportions of prescribed medications that were taken, based on opening of MEMS caps. For example, if 27 bottle openings occurred and 28 doses were prescribed, adherence was $27 / 28$ or $96.4 \%$. However, we considered a dose to be taken only if bottle opening occurred during a proper dose timing interval specific to the dosing frequency of the prescribed medication (e.g., twice daily or three times daily). Specifically, participants were categorized as being adherent to a prescribed antibiotic if they opened the electronic bottle cap within $67 \%$ of the prescribed dosing interval. The basis for applying this percentage was to avoid overcalculations of compliance for patients who may have opened the bottle cap within a few minutes of time. The following time frames after a prior dose were used to determine that the dose was properly taken (adherent): intervals of $12 \pm 4 \mathrm{~h}$ for a twice-daily antibiotic, $8 \pm 2 \mathrm{~h} 40 \mathrm{~min}$ for a three-times-daily antibiotic, and $6 \pm 2 \mathrm{~h}$ for a four-times-daily antibiotic. If participants continued to open their pill bottle beyond the specified duration of therapy, the later doses were not included in the adherence calculation.

Prior to study commencement, we estimated power calculations to achieve $80 \%$ power to detect a $10 \%$ difference in adherence between treatment outcomes (responders versus nonresponders). The power calculations assumed a significance level of an $\alpha$ value of 0.05 with $90 \%$ and $80 \%$ adherence rates between treatment outcomes. We also assumed a standard deviation of a delta value of 0.15 and a ratio of responders to nonresponders of 0.489 , based on previous studies using MEMS-based adher- ence and treatment outcomes of patients with skin infections $(6,23)$. Using these assumptions, we estimated that we would need 84 participants to detect a difference in clinical outcomes between groups.

Data analyses were performed by using SAS version 9.3 (SAS Institute, USA). Bivariate analysis was used to compare variables from the risk factor questionnaire hypothesized to be associated with poor clinical response. Bivariate analyses were assessed by using odds ratios (ORs), 95\% confidence intervals (CIs), and the associated $P$ values. All variables with a $P$ value of $<0.20$ in the bivariate analysis were included in a multivariate logistic regression analysis predicting poor clinical response. Multicolinearity for the logistic regression model was assessed by condition indices and variance decomposition proportions using a macro developed for use with the SAS system. Backwards elimination was performed by using the likelihood ratio test to find the best model. Models were examined for goodness of fit by using the Hosmer-Lemeshow statistic. Linear regression was utilized to examine predictors from the risk factor questionnaire hypothesized to be associated with adherence. Mean adherence rates, standard deviations, and the associated $P$ values were calculated. All variables were considered significant at an $\alpha$ value of 0.05 .

\section{RESULTS}

Among the 188 participants who consented to be in the study, 87 (46\%) were confirmed as being eligible and returned the MEMS cap to study personnel. Of the 101 participants not included in the analysis, the reasons for exclusion were as follows: they met exclusion criteria of bacteremia (1 participant), osteomyelitis (15 participants), or hardware- or device-associated infection (9 participants); were discharged without oral antibiotics (31 participants); did not have a confirmed diagnosis of $S$. aureus skin infection (7 participants); did not use or return the MEMS cap (31 participants); and discontinued participation prior to discharge (7 participants). Among the 87 participants included in the analysis, $71 \%$ were male, with an average age of 43 years, and $44 \%$ of the participants were of Hispanic ethnicity (Table 1).

The mean rate of adherence to antibiotic therapy using MEMS data was $57 \%$, which was different from a self-reported adherence rate of $96 \%(P<0.0001)$ (Fig. 1). Common reasons reported for missed doses were as follows: the participant was away from home (32\%), was asleep when a dose was supposed to be taken (14\%), or forgot to take the dose (14\%); the medication made the participant feel sick (12\%); and there were too many pills to take (11\%). Participants also reported that the most common reminder method used was taking the medication(s) with meals (74\%). Table 2 shows factors analyzed for their association with adherence. Poor adherence was associated with participants being discharged with more than one antibiotic $(P=0.01)$, not seeing the same health care provider for care $(P=0.02)$, and not feeling that they had a regular health care provider $(P=0.05)$. Appropriate antibiotic therapy was prescribed for $85(98 \%)$ patients. There was 1 patient in the poor-clinical-response group and 1 patient in the successful-response group who received inappropriate antibiotic therapy according to culture and susceptibility data $(P=0.99)$.

Forty participants (46\%) experienced a poor clinical response in the study. Poor clinical responses were due to the following: a relapse of skin infection $(9 / 40 ; 22.5 \%)$; a new skin infection (12/ $40 ; 30 \%)$; receipt of prolonged antibiotic therapy, receipt of new antibiotic therapy, or change in therapy for skin infection $(16 / 40$; $40 \%)$; and a new incision-and-drainage procedure (3/40; $7.5 \%)$. In our bivariate analysis, lower adherence trended toward a significant association with poor clinical response $(P=0.06)$ (Table $1)$. In the multivariable analysis, lower adherence was an independent risk factor for poor clinical outcome (OR, 0.16; 95\% CI, 0.02 
TABLE 1 Bivariate analysis of risk factors associated with poor clinical response after 30 days ${ }^{a}$

\begin{tabular}{|c|c|c|c|c|c|}
\hline Variable & \multicolumn{3}{|c|}{ Value for group } & $\begin{array}{l}\text { Odds ratio } \\
\text { (95\% confidence interval) }\end{array}$ & $P$ value \\
\hline Mean \pm SD & $56.9 \pm 24.9$ & $51.4 \pm 24.8$ & $61.5 \pm 24.3$ & $0.19(0.03-1.1)$ & 0.06 \\
\hline Median (range) & $55.6(0-100)$ & $50.9(4.8-96.4)$ & $62.5(0-100)$ & & \\
\hline TMP-SMX & $46(51)$ & $23(58)$ & $23(49)$ & Ref. & \\
\hline Clindamycin & $29(33)$ & $12(30)$ & $17(36)$ & $0.71(0.28-1.8)$ & 0.47 \\
\hline Other $^{b}$ & $12(14)$ & $5(12)$ & $7(15)$ & $0.71(0.20-2.6)$ & 0.61 \\
\hline \multicolumn{6}{|l|}{ Dosage } \\
\hline BID & $34(39)$ & $14(35)$ & $20(42)$ & Ref. & \\
\hline TID & $29(33)$ & $12(30)$ & $17(36)$ & $2.0(0.70-5.8)$ & 0.20 \\
\hline \multicolumn{6}{|l|}{ Demographics } \\
\hline Mean \pm SD & $43.0 \pm 13.6$ & $44.2 \pm 12.6$ & $42.0 \pm 14.5$ & $1.01(0.98-1.04)$ & 0.46 \\
\hline Median (range) & $45.0(19-79)$ & $46(19-62)$ & $41(19-79)$ & & \\
\hline \multicolumn{6}{|l|}{ No. (\%) of subjects of gender } \\
\hline Female & $25(29)$ & $11(28)$ & $14(30)$ & $1.12(0.44-2.9)$ & 0.81 \\
\hline Male & $62(71)$ & $29(73)$ & $33(70)$ & & \\
\hline \multicolumn{6}{|l|}{ No. (\%) of patients of ethnicity/race } \\
\hline Hispanic & $37(44)$ & $16(42)$ & $21(45)$ & Ref. & \\
\hline African American & $29(34)$ & $13(34)$ & $16(34)$ & $1.1(0.40-2.8)$ & 0.90 \\
\hline Caucasian & $14(17)$ & $8(21)$ & $6(13)$ & $1.8(0.51-6.1)$ & 0.38 \\
\hline Other ${ }^{c}$ & $5(5)$ & $1(3)$ & $4(9)$ & $0.33(0.03-3.3)$ & 0.34 \\
\hline \multicolumn{6}{|l|}{ No. (\%) of patients with education level } \\
\hline Some high school or less & $16(18)$ & $9(22)$ & $7(15)$ & Ref. & \\
\hline High school graduate & $67(77)$ & $28(70)$ & $39(82)$ & $0.59(0.19-1.7)$ & 0.30 \\
\hline Median (range) & $1.0(0-9)$ & $1.5(0-9)$ & $1.0(0-8)$ & & \\
\hline \multicolumn{6}{|l|}{ No. (\%) of patients with history of: } \\
\hline Diabetes & $36(41)$ & $13(33)$ & $23(49)$ & $0.50(0.21-1.2)$ & 0.12 \\
\hline S. aureus infection & $14(16)$ & $7(18)$ & $7(15)$ & $1.2(0.39-3.8)$ & 0.74 \\
\hline Skin infection & $19(21)$ & $11(28)$ & $8(17)$ & $1.8(0.66-5.2)$ & 0.24 \\
\hline Surgical procedure & $9(10)$ & $4(10)$ & $5(11)$ & $0.93(0.23-3.7)$ & 0.92 \\
\hline Health care exposure $e^{d}$ & $43(49)$ & $20(50)$ & $23(49)$ & $1.04(0.45-2.4)$ & 0.92 \\
\hline Admission to a long-term-care facility & $18(21)$ & $11(28)$ & $7(15)$ & $2.2(0.75-6.3)$ & 0.15 \\
\hline Receipt of antibiotics & $47(54)$ & $23(58)$ & $24(51)$ & $1.3(0.56-3.0)$ & 0.54 \\
\hline Eczema & $5(6)$ & $2(5)$ & $3(6)$ & $0.79(0.13-5.0)$ & 0.80 \\
\hline HIV/AIDS & $8(9)$ & $2(5)$ & $6(13)$ & & 0.28 \\
\hline MRSA colonization & $3(3)$ & $1(3)$ & $2(4)$ & & 0.99 \\
\hline \multicolumn{6}{|l|}{$\begin{array}{l}\text { No. }(\%) \text { of patients with social history in } \\
\text { previous } 12 \text { mo of: }\end{array}$} \\
\hline Incarceration & $7(8)$ & $4(10)$ & $3(6)$ & $1.7(0.35-7.9)$ & 0.51 \\
\hline Homelessness & $20(23)$ & $7(18)$ & $13(28)$ & $0.56(0.19-1.6)$ & 0.27 \\
\hline Illicit drug use & $28(32)$ & $9(23)$ & $19(40)$ & $0.43(0.17-1.1)$ & 0.08 \\
\hline
\end{tabular}

${ }^{a}$ TMP-SMX, trimethoprim-sulfamethoxazole; BID, twice a day; TID, three times a day; QID, four times a day; Ref., reference group.

${ }^{b}$ Other antibiotics include amoxicillin-clavulanate $(n=4)$, linezolid $(n=3)$, cephalexin $(n=2)$, dicloxacillin $(n=1)$, and doxycycline $(n=1)$,

${ }^{c}$ Other ethnicities include Asian/Pacific Islander, mixed race, and reported unknown/unsure race or ethnicity.

${ }^{d}$ Health care exposure is defined as being seen at an emergency department or an urgent-care center, being admitted to a hospital, or having spent time at a long-term-care facility. 


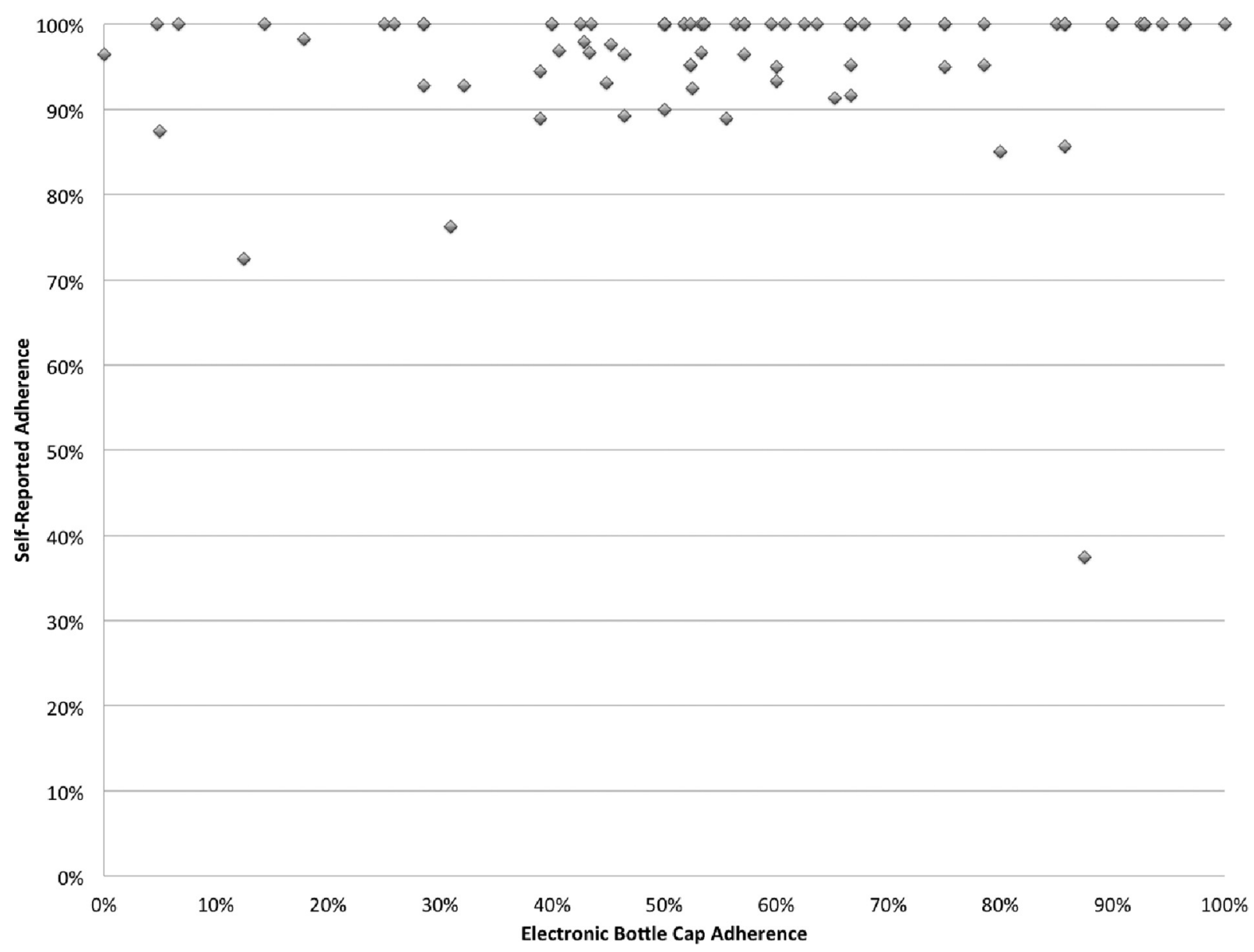

FIG 1 Self-reported adherence compared to electronic bottle cap adherence.

to $0.99 ; P=0.049$ ) (Table 3 ). Lack of comorbid diabetes mellitus (OR, $0.40 ; 95 \%$ CI, 0.15 to $1.0 ; P=0.05$ ) and lack of illicit drug use in the previous 12 months (OR, 0.36 ; $95 \% \mathrm{CI}, 0.13$ to $0.99 ; P=$ 0.048) were also independent risk factors for poor clinical outcome. Results for the clinical response at 14 days were similar to those at 30 days (data not shown).

\section{DISCUSSION}

Skin infections are a common clinical problem resulting in substantial clinical morbidity, hospitalization, and cost $(1,2,24)$. In this study, postdischarge adherence to antibiotic therapy for $S$. aureus skin infection was low (57\%) and associated with poor clinical outcome. This low adherence contrasted with the high levels of adherence (96\%) that participants reported in a confidential interview. Poor clinical outcome was independently associated with relapse or recurrent infection. While the number of relapse/recurrent infections among the cohort is worrisome, these numbers are, however, consistent with data for other cohorts in which recurrent infection after methicillin-resistant $S$. aureus (MRSA) or S. aureus infection exceeded 50\% $(5,8)$. Our data suggest that adherence may explain some of the relapses that occur among patients with skin infections.

Poor adherence to antibiotic therapy is a common problem that is highlighted in this investigation. While ours is the first investigation to examine the association between clinical outcome and adherence among patients with a skin infection, other studies have reported similarly low adherence to antibiotic regimens. In a French study of 37 patients with a variety of different infections who were being discharged with antibiotics after hospitalization, $43 \%$ reported nonadherence to the prescribed antibiotic regimen (15). Another European investigation among patients with acute cough who were prescribed outpatient antibiotics found that $30 \%$ of patients reported that they did not consume any antibiotics and that only $44 \%$ reported consuming the entire prescribed treatment course (25). Similarly, a study of patients in Portugal reported a rate of adherence to oral antibiotics in community pharmacies of $58 \%$ (26). A meta-analysis of community-based antibiotics found that the mean rate of adherence was $62.2 \%(95 \%$ CI, 56.4 to $68.0 \%)(26)$.

In our investigation, poor adherence was associated with patients being discharged with more than one antibiotic, not seeing the same health care provider for care, and not feeling that they had a regular health care provider. These data are consistent with previously reported theoretical constructs and empirical data (14, $21,27)$. Other studies found that poor adherence was associated with a higher number of daily doses of the antibiotic $(16,28-30)$, longer antibiotic treatment duration $(25,26,28)$, increasing age, difficulty in buying the antibiotic, duration of treatment, difficulty with ingestion, and satisfaction with the information given by the physician (26). 
TABLE 2 Linear regression analysis of risk factors associated with MEMS adherence $^{c}$

\begin{tabular}{lll}
\hline Variable & $\begin{array}{l}\text { Mean } \% \\
\text { adherence } \pm \mathrm{SD}^{a}\end{array}$ & $P$ value \\
\hline Age & & 0.82
\end{tabular}

Gender

Female

Male

Race/ethnicity

Hispanic

African American

Caucasian

Other $^{b}$

Education

Some high school or less

High school graduate

Completed university

$52.4 \pm 30.1$

Charlson comorbidity index

Beliefs and attitudes of participants One can fight off an infections just as well without antibiotics as with antibiotics

\section{Yes}

No

Antibiotics are very toxic

Yes

No

Antibiotics will improve the quality of your life

Yes

No

Taking antibiotics is too much trouble for what you get out of it Yes

No

Medication factors

Dosage

BID

TID

QID

Duration

Discharged with $>1$ antibiotic

Yes

No

Takes daily medication for other conditions

Yes

No

Self-reported adherence

Rating of health care received for skin infection

See the same health care provider for care

None of the time

Some of the time

Most or all of the time

Feel that they have a regular health

$$
\text { care provider }
$$

Yes

No
$53.1 \pm 25.4$

$58.4 \pm 24.7$

$57.5 \pm 25.6$

$53.6 \pm 25.5$

$62.5 \pm 23.7$

$64.8+23.3$

$57.6 \pm 24.1$

$62.4+18.1$

Ref.

0.36

0.54

0.28

Ref.

0.45

0.47

0.97

$60.1 \pm 21.1$

0.45

$55.7 \pm 26.3$

$58.5 \pm 23.9$

$54.9 \pm 26.3$

$56.9 \pm 25.1$

$55.7 \pm 0.0$

0.86

$54.2 \pm 26.1$

$58.5 \pm 23.4$

$61.6 \pm 28.1$

$52.7 \pm 21.1$

$54.8 \pm 23.7$

$49.7 \pm 23.3$

$63.0 \pm 24.8$

$60.1 \pm 21.9$

$53.1 \pm 27.1$

$51.7 \pm 24.4$

$66.9 \pm 25.7$

$63.5 \pm 18.7$

Ref.

0.28

0.18

0.25

0.01

0.20

0.56

0.57

$68.4 \pm 15.2$

$54.4 \pm 25.9$

Ref.

0.02

0.16
TABLE 2 (Continued)

\begin{tabular}{|c|c|c|}
\hline Variable $^{c}$ & $\begin{array}{l}\text { Mean } \% \\
\text { adherence } \pm \mathrm{SD}^{a}\end{array}$ & $P$ value \\
\hline \multicolumn{3}{|c|}{ Did a health care provider: } \\
\hline \multicolumn{3}{|c|}{$\begin{array}{l}\text { Say that it is important to take every } \\
\text { dose of the antibiotic }\end{array}$} \\
\hline Yes & $58.6 \pm 23.5$ & 0.21 \\
\hline No & $48.6 \pm 34.3$ & \\
\hline \multicolumn{3}{|c|}{$\begin{array}{l}\text { Explain why it was important to take } \\
\text { every dose of the antibiotic }\end{array}$} \\
\hline Yes & $57.4 \pm 24.0$ & 0.86 \\
\hline No & $56.4 \pm 28.2$ & \\
\hline \multicolumn{3}{|c|}{$\begin{array}{l}\text { Ask whether you had trouble taking } \\
\text { all antibiotics }\end{array}$} \\
\hline Yes & $59.6 \pm 20.9$ & 0.57 \\
\hline No & $55.5 \pm 27.6$ & \\
\hline \multicolumn{3}{|c|}{$\begin{array}{l}\text { Explain exactly how and when to take } \\
\text { the antibiotics }\end{array}$} \\
\hline Yes & $61.2 \pm 23.7$ & 0.07 \\
\hline No & $50.8 \pm 26.5$ & \\
\hline
\end{tabular}

Beliefs related to antibiotics

You can fight off an infection just as well without antibiotics as you can with antibiotics

\section{Agree \\ Disagree \\ These antibiotics are very toxic}

Agree

Disagree

These antibiotics will improve the quality of your life

Agree

Disagree

Taking these antibiotics is too much trouble for what you get out of it

$$
\begin{aligned}
& \text { Agree } \\
& \text { Disagree }
\end{aligned}
$$

$61.1 \pm 21.9$

$56.7 \pm 25.1$

$51.8 \pm 27.7$

$59.9 \pm 25.3$

$57.6 \pm 24.6$

0.48

$48.5 \pm 30.4$

$63.4 \pm 27.2$

$59.2 \pm 23.2$

Trust of subjects in doctors, nurses, or health care providers to:

Offer you high-quality medical care

Completely

Mostly

Somewhat/a little

$55.6 \pm 25.3$

Ref.

$54.9 \pm 25.6$

0.92

Be more concerned about your health than about the time, effort, and costs of treating you

Completely

Mostly

Somewhat/a little

$67.7 \pm 21.0$

0.16

Prescribe the best antibiotics

Completely

Mostly

Somewhat/a little

$53.9 \pm 23.7$

Ref.

$65.7+31.8 \quad 0.11$

$62.4 \pm 19.0 \quad 0.37$

$57.1 \pm 24.2 \quad$ Ref.

$53.0 \pm 33.8 \quad 0.71$

$56.3 \pm 30.0 \quad 0.95$

${ }^{a}$ Ref., reference group.

${ }^{b}$ Other ethnicities include Asian/Pacific Islander, mixed race, and reported unknown/ unsure race or ethnicity.

${ }^{c}$ Factors significantly associated $(P \leq 0.05)$ with MEMS adherence are bolded.

We found that lower adherence was a significant risk factor for poor clinical outcome. Few investigations have examined both adherence and clinical outcome for acute infectious diseases. One investigation found no association between clinical outcomes of 
TABLE 3 Multivariate analysis of risk factors associated with poor clinical response after 30 days

\begin{tabular}{lll}
\hline Variable & $\begin{array}{l}\text { Odds ratio } \\
(95 \% \text { confidence interval })\end{array}$ & $P$ value \\
\hline $\begin{array}{l}\text { Overall electronically measured } \\
\quad \text { adherence }\end{array}$ & $0.16(0.02-0.99)$ & 0.049 \\
$\begin{array}{l}\text { Diabetes } \\
\text { Illicit drug use }\end{array}$ & $0.40(0.15-1.0)$ & 0.05 \\
\hline
\end{tabular}

cough based on patient-reported adherence (25). This lack of association may be based on the fact that antibiotics for bronchitis have no effect on clinical outcome in the majority of patients with bronchitis (31). Our investigation also found that better adherence was associated with diabetes and illicit drug use. While the reason why these two groups may have better adherence is not clear, we hypothesize that the relationship may stem from the fact that these groups of patients frequently experience skin infections and may be more knowledgeable about the importance of taking their antibiotics as prescribed. Alternatively, clinicians may have known that these factors were associated with worse outcomes and may have treated the patients more conservatively in the hospital, thus discharging them when they had a less severe skin infection than those of patients without diabetes or illicit drug use.

Methods to improve adherence for acute infections are relatively understudied. Health care providers can enhance adherence by discussing the value of completing the regimen with their patient, making the regimen simple, and customizing the regimen to the patient's lifestyle. One recent randomized trial suggested that medication counseling may improve adherence to antibiotics (32), but larger studies are needed. New methods of managing chronic diseases, such as text message reminders and smart phone applications, have had success in improving adherence (33); however, these innovations have not been utilized in the management of acute infections. Newer longeracting antibiotics have recently been approved for the treatment of skin infections, such as dalbavancin and oritavancin, which are dosed one weekly $(34,35)$. The use of these antibiotics may alleviate challenges associated with adherence to antibiotic therapy for patients for whom this is an appropriate treatment option. However, their ability to improve outcomes over oral therapy is unproven at this time.

There are some limitations to our investigation. The adherence data analyzed were collected by using electronic bottle caps. Cap openings do not always necessarily correspond to the actual medication being taken. Participants may have removed multiple doses at one cap opening in order to put them into pillboxes, in which case the cap openings underestimate actual adherence (36). Additionally, the participants were enrolled from a single center, and findings may not be generalizable to other populations. However, the patient population at our institution is similar to those of many community hospitals and is ethnically diverse. We also relied on participants to self-report social risk factors. Participants may be reticent to acknowledge less socially acceptable risk factors such as incarceration or illicit substance use. Nevertheless, in a previous investigation at this institution using this instrument, risk factors that may be considered socially undesirable were significantly associated with
MRSA risk (37), suggesting that the survey has validity and limited bias.

There are strengths to our investigation. First, this is the first study to examine the association between clinical outcome and adherence to antibiotic therapy postdischarge among patients hospitalized with a skin infection. This is also the first investigation to find an association between adherence to postdischarge antibiotic therapy and poor clinical outcome. Second, our measure of adherence was strong, as we employed electronic bottle caps to measure adherence. This measure is superior to self-reporting, pill counts, and pharmacy records as it correlates better with clinical outcomes (36). Third, we studied only participants with $S$. aureus-associated skin infection, a condition known to have a high rate of recurrence of infection $(5,8)$. This high rate provided reasonable power to examine the relationship between infection and clinical outcome. Finally, we used a theoretical construct to examine factors associated with medication adherence. Most other investigations have focused on clinical factors and did not measure participants' beliefs and attitudes, which may be important predictors of adherence $(38,39)$.

In conclusion, we found that low adherence to postdischarge antibiotic therapy after hospitalization for skin infection was associated with a higher chance of clinical failure. Patients typically overstate their medication adherence, which may make identification of those at risk for nonadherence and poor outcomes challenging. Further studies are needed to determine methods to improve antibiotic adherence and clinical outcomes after hospitalization for a skin infection.

\section{ACKNOWLEDGMENTS}

Financial support was provided in part by an unrestricted grant from Pfizer, Inc.

We thank Grace Tagudar, Ramiro Correa, and Clinical Microbiology Laboratory at Harbor-UCLA Medical Center personnel for their assistance with this investigation. We also thank the patients for participating in this investigation.

L.G.M. has received grants from Pfizer and has served as a consultant for Durata Therapeutics, Melinta, Merck, and Theravance.

\section{FUNDING INFORMATION}

This work, including the efforts of Megan Nguyen, Jina Jung, Raul Macias-Gil, Larissa May, and Loren G. Miller, was funded by Pfizer (Pfizer Inc.).

The funder had no role in the study design, data collection, analysis, or interpretation, or manuscript preparation.

\section{REFERENCES}

1. Ray GT, Suaya JA, Baxter R. 2013. Incidence, microbiology, and patient characteristics of skin and soft-tissue infections in a U.S. population: a retrospective population-based study. BMC Infect Dis 13:252. http://dx .doi.org/10.1186/1471-2334-13-252.

2. Miller LG, Eisenberg DF, Liu H, Chang CL, Wang Y, Luthra R, Wallace A, Fang C, Singer J, Suaya JA. 2015. Incidence of skin and soft tissue infections in ambulatory and inpatient settings, 2005-2010. BMC Infect Dis 15:362. http://dx.doi.org/10.1186/s12879-015-1071-0.

3. David MZ, Daum RS. 2010. Community-associated methicillin-resistant Staphylococcus aureus: epidemiology and clinical consequences of an emerging epidemic. Clin Microbiol Rev 23:616-687. http://dx.doi.org/10 .1128/CMR.00081-09.

4. Mulligan ME, Murray-Leisure KA, Ribner BS, Standiford HC, John JF, Korvick JA, Kauffman CA, Yu VL. 1993. Methicillin-resistant Staphylococcus aureus: a consensus review of the microbiology, pathogenesis, and epidemiology with implications for prevention and manage- 
ment. Am J Med 94:313-328. http://dx.doi.org/10.1016/0002-9343(93) 90063-U.

5. Fritz SA, Hogan PG, Hayek G, Eisenstein KA, Rodriguez M, Epplin EK, Garbutt J, Fraser VJ. 2012. Household versus individual approaches to eradication of community-associated Staphylococcus aureus in children: a randomized trial. Clin Infect Dis 54:743-751. http://dx.doi.org/10.1093 /cid/cir919.

6. Miller LG, Quan C, Shay A, Mostafaie K, Bharadwa K, Tan N, Matayoshi K, Cronin J, Tan J, Tagudar G, Bayer AS. 2007. A prospective investigation of outcomes after hospital discharge for endemic, community-acquired methicillin-resistant and -susceptible Staphylococcus aureus skin infection. Clin Infect Dis 44:483-492. http://dx.doi.org/10.1086 1511041.

7. Crum-Cianflone N, Weekes J, Bavaro M. 2009. Recurrent communityassociated methicillin-resistant Staphylococcus aureus infections among HIV-infected persons: incidence and risk factors. AIDS Patient Care STDs 23:499-502. http://dx.doi.org/10.1089/apc.2008.0240.

8. Graber CJ, Jacobson MA, Perdreau-Remington F, Chambers HF, Diep BA. 2008. Recurrence of skin and soft tissue infection caused by methicillin-resistant Staphylococcus aureus in a HIV primary care clinic. J Acquir Immune Defic Syndr 49:231-233. http://dx.doi.org/10 .1097/QAI.0b013e318183a947.

9. Miller LG, Eells SJ, David MZ, Ortiz N, Taylor AR, Kumar N, Cruz D, Boyle-Vavra S, Daum RS. 2015. Staphylococcus aureus skin infection recurrences among household members: an examination of host, behavioral, and pathogen-level predictors. Clin Infect Dis 60:753-763. http://dx .doi.org/10.1093/cid/ciu943.

10. Eells SJ, McKinnell JA, Wang AA, Green NL, Whang D, O'Hara P, Brown ML, Miller LG. 2013. A comparison of clinical outcomes between healthcare-associated infections due to community-associated methicillin-resistant Staphylococcus aureus strains and healthcare-associated methicillin-resistant S. aureus strains. Epidemiol Infect 141:2140-2148. http: //dx.doi.org/10.1017/S0950268812002634.

11. Mbuagbaw L, Sivaramalingam B, Navarro T, Hobson N, Keepanasseril A, Wilczynski NJ, Haynes RB, Patient Adherence Review Team. 2015. Interventions for enhancing adherence to antiretroviral therapy (ART): a systematic review of high quality studies. AIDS Patient Care STDs 29:248 266. http://dx.doi.org/10.1089/apc.2014.0308.

12. Hedna K, Hakkarainen KM, Gyllensten H, Jonsson AK, Andersson Sundell K, Petzold M, Hagg S. 2015. Adherence to antihypertensive therapy and elevated blood pressure: should we consider the use of multiple medications? PLoS One 10:e0137451. http://dx.doi.org/10.1371 /journal.pone.0137451.

13. Chew BH, Sherina MS, Hassan NH. 2015. Association of diabetesrelated distress, depression, medication adherence, and health-related quality of life with glycated hemoglobin, blood pressure, and lipids in adult patients with type 2 diabetes: a cross-sectional study. Ther Clin Risk Manag 11:669-681. http://dx.doi.org/10.2147/TCRM.S81623.

14. Osterberg L, Blaschke T. 2005. Adherence to medication. N Engl J Med 353:487-497. http://dx.doi.org/10.1056/NEJMra050100.

15. Faure H, Leguelinel-Blache G, Salomon L, Poujol H, Kinowski JM, Sotto A. 2014. Assessment of patient adherence to anti-infective treatment after returning home. Med Mal Infect 44:417-422. http://dx.doi.org /10.1016/j.medmal.2014.08.001.

16. Llor C, Sierra N, Hernandez S, Moragas A, Hernandez M, Bayona C, Miravitlles M. 2009. The higher the number of daily doses of antibiotic treatment in lower respiratory tract infection the worse the compliance. J Antimicrob Chemother 63:396-399. http://dx.doi.org/10.1093 /jac/dkn472.

17. Stevens DL, Bisno AL, Chambers HF, Dellinger EP, Goldstein EJ, Gorbach SL, Hirschmann JV, Kaplan AH, Montoya JG, Wade JC. 2014. Practice guidelines for the diagnosis and management of skin and soft tissue infections: 2014 update by the Infectious Diseases Society of America. Clin Infect Dis 59:e10-e52. http://dx.doi.org/10.1093/cid/ciu296.

18. Eron LJ, Lipsky BA, Low DE, Nathwani D, Tice AD, Volturo GA. 2003. Managing skin and soft tissue infections: expert panel recommendations on key decision points. J Antimicrob Chemother 52:i3-i17. http://dx.doi .org/10.1093/jac/dkg466.

19. Yang ES, Tan J, Eells S, Rieg G, Tagudar G, Miller LG. 2010. Body site colonization in patients with community-associated methicillin-resistant Staphylococcus aureus and other types of S. aureus skin infections. Clin Microbiol Infect 16:425-431. http://dx.doi.org/10.1111/j.1469-0691.2009 .02836.x.
20. Golin CE, Liu H, Hays RD, Miller LG, Beck CK, Ickovics J, Kaplan AH, Wenger NS. 2002. A prospective study of predictors of adherence to combination antiretroviral medication. J Gen Intern Med 17:756-765. http://dx.doi.org/10.1046/j.1525-1497.2002.11214.x.

21. DiMatteo MR, DiNicola DD. 1982. Achieving patient compliance: the psychology of the medical practitioner's role. Pergamon Press, New York, NY.

22. Miller LG, Hays RD. 2000. Measuring adherence to antiretroviral medications in clinical trials. HIV Clin Trials 1:36-46. http://dx.doi.org/10 .1310/ENXW-95PB-5NGW-1F40.

23. Miller LG, Liu H, Hays RD, Golin CE, Beck CK, Asch SM, Ma Y, Kaplan AH, Wenger NS. 2002. How well do clinicians estimate patients' adherence to combination antiretroviral therapy? J Gen Intern Med 17:111. http://dx.doi.org/10.1046/j.1525-1497.2002.09004.x.

24. Labreche MJ, Lee GC, Attridge RT, Mortensen EM, Koeller J, Du LC Nyren NR, Trevino LB, Trevino SB, Pena J, Mann MW, Munoz A, Marcos Y, Rocha G, Koretsky S, Esparza S, Finnie M, Dallas SD, Parchman ML, Frei CR. 2013. Treatment failure and costs in patients with methicillin-resistant Staphylococcus aureus (MRSA) skin and soft tissue infections: a South Texas Ambulatory Research Network (STARNet) study. J Am Board Fam Med 26:508-517. http://dx.doi.org/10.3122/jabfm.2013 .05.120247.

25. Francis NA, Gillespie D, Nuttall J, Hood K, Little P, Verheij T, Coenen S, Cals JW, Goossens H, Butler CC, GRACE Project Group. 2012. Antibiotics for acute cough: an international observational study of patient adherence in primary care. Br J Gen Pract 62:e429-e437. http://dx .doi.org/10.3399/bjgp12X649124.

26. Fernandes M, Leite A, Basto M, Nobre MA, Vieira N, Fernandes R, Nogueira P, Nicola PJ. 2014. Non-adherence to antibiotic therapy in patients visiting community pharmacies. Int J Clin Pharm 36:86-91. http: //dx.doi.org/10.1007/s11096-013-9850-4.

27. Hansen RA, Voils CI, Farley JF, Powers BJ, Sanders LL, Sleath B, Maciejewski ML. 2015. Prescriber continuity and medication adherence for complex patients. Ann Pharmacother 49:293-302. http://dx.doi.org /10.1177/1060028014563266.

28. Llor C, Hernandez S, Bayona C, Moragas A, Sierra N, Hernandez M, Miravitlles M. 2013. A study of adherence to antibiotic treatment in ambulatory respiratory infections. Int J Infect Dis 17:e168-e172. http: //dx.doi.org/10.1016/j.ijid.2012.09.012.

29. Sclar DA, Tartaglione TA, Fine MJ. 1994. Overview of issues related to medical compliance with implications for the outpatient management of infectious diseases. Infect Agents Dis 3:266-273.

30. Kardas P. 2002. Patient compliance with antibiotic treatment for respiratory tract infections. J Antimicrob Chemother 49:897-903. http://dx.doi .org/10.1093/jac/dkf046.

31. Smith SM, Fahey T, Smucny J, Becker LA. 2014. Antibiotics for acute bronchitis. Cochrane Database Syst Rev 3:CD000245. http://dx.doi.org/10 .1002/14651858.CD000245.pub3.

32. Pham JA, Pierce W, Muhlbaier L. 2013. A randomized, controlled study of an educational intervention to improve recall of auxiliary medication labeling and adherence to antibiotics. Sage Open Med 2:2050312113490420. http://dx.doi.org/10.1177/2050312113490420.

33. Hamine S, Gerth-Guyette E, Faulx D, Green BB, Ginsburg AS. 2015. Impact of mHealth chronic disease management on treatment adherence and patient outcomes: a systematic review. J Med Internet Res 17:e52. http://dx.doi.org/10.2196/jmir.3951.

34. Zervou FN, Zacharioudakis IM, Mylonakis E. 2014. Weekly dalbavancin was noninferior to daily vancomycin for acute bacterial skin infection in adults. Ann Intern Med 161:JC9. http://dx.doi.org/10.7326/0003-4819 -161-8-201410210-02009.

35. Corey GR, Good S, Jiang H, Moeck G, Wikler M, Green S, Manos P, Keech R, Singh R, Heller B, Bubnova N, O'Riordan W, SOLO II Investigators. 2015. Single-dose oritavancin versus 7-10 days of vancomycin in the treatment of Gram-positive acute bacterial skin and skin structure infections: the SOLO II noninferiority study. Clin Infect Dis 60:254262. http://dx.doi.org/10.1093/cid/ciu778.

36. Liu H, Golin CE, Miller LG, Hays RD, Beck CK, Sanandaji S, Christian J, Maldonado T, Duran D, Kaplan AH, Wenger NS. 2001. A comparison study of multiple measures of adherence to HIV protease inhibitors. Ann Intern Med 134:968-977. http://dx.doi.org/10.7326/0003-4819-134-10 $-200105150-00011$.

37. Miller LG, Perdreau-Remington F, Bayer AS, Diep B, Tan N, Bhar- 
adwa K, Tsui J, Perlroth J, Shay A, Tagudar G, Ibebuogu U, Spellberg B. 2007. Clinical and epidemiologic characteristics cannot distinguish community-associated methicillin-resistant Staphylococcus aureus infection from methicillin-susceptible S. aureus infection: a prospective investigation. Clin Infect Dis 44:471-482. http://dx.doi.org/10 $.1086 / 511033$

38. Allen LaPointe NM, Ou FS, Calvert SB, Melloni C, Stafford JA, Harding T, Peterson ED, Alexander KP. 2011. Association between patient beliefs and medication adherence following hospitalization for acute coronary syndrome. Am Heart J 161:855-863. http://dx.doi.org/10.1016/j.ahj.2011 .02 .009 .

39. Horne R, Chapman SC, Parham R, Freemantle N, Forbes A, Cooper V. 2013. Understanding patients' adherence-related beliefs about medicines prescribed for long-term conditions: a meta-analytic review of the necessity-concerns framework. PLoS One 8:e80633. http://dx.doi.org/10.1371 /journal.pone.0080633. 